\title{
Pediatric Surgical Admissions and Their Outcomes at Adama Hospital Medical College: A Facility Based Cross Sectional Study
}

\author{
Tsegaye Ketema ${ }^{1,}$, , Sileshi Garoma Abeya ${ }^{1}$, Kalide Abdela ${ }^{2}$, Tolossa Eticha Chaka ${ }^{3}$ \\ ${ }^{1}$ Department of Public Health, Adama Hospital Medical College, Adama, Ethiopia \\ ${ }^{2}$ Department of Surgery, Adama Hospital Medical College, Adama, Ethiopia \\ ${ }^{3}$ Department of Pediatrics and Child Health, Adama Hospital Medical College, Adama, Ethiopia
}

Email address:

ketematsegaye540@yahoo.com (T. Ketema), garomaabe@gmail.com (S. G. Abeya), Khalid.esmeal@yahoo.com (K. Abdela), tecb2006@gmail.com (T. E. Chaka)

${ }^{*}$ Corresponding author

\section{To cite this article:}

Tsegaye Ketema, Sileshi Garoma Abeya, Kalide Abdela, Tolossa Eticha Chaka. Pediatric Surgical Admissions and Their Outcomes at Adama Hospital Medical College: A Facility Based Cross Sectional Study. American Journal of Pediatrics. Vol. 3, No. 4, 2017 , pp. $23-27$. doi: 10.11648/j.ajp.20170304.12

Received: May 5, 2017; Accepted: May 26, 2017; Published: August 30, 2017

\begin{abstract}
Pediatric surgical admissions dramatically increased throughout the world as a result of increased trauma, emergency diseases and survival of congenital diseases. So, Facility based cross sectional study was conducted to identify the common pediatric (Age $\leq 15$ years) surgical admissions and their outcomes at Adama Hospital Medical College. All admitted surgical patients from Jun 1, 2014 to June 30, 2015 were included in the study. Data abstraction tool was constructed to retrieve information from charts. Data was entered to SPSS version 20. Descriptive and analytic studies were performed. P value $\leq 0.05$ with $95 \%$ confidence interval (CI) was used to interpret the findings. The mean age of study participants was 6 years \pm 4.5 SD. Males were 276 (71.9\%) making male to female ratio of 2.5:1. Gastrointestinal conditions (33.8\%) were commonest causes of admissions followed by trauma $(25.5 \%)$ and congenital anomalies $(19 \%)$. There were five deaths resulting in a mortality rate of $1.3 \%$. Factors associated with death were: delay in presentation, prolonged length of stay in hospital and delay in intervention. Shorter time of presentation to intervention $(<6 \mathrm{hrs})$ was found to be significantly associated with the favorable outcomes [Adjusted Odds Ratio (AOR): 36.4, 95\% CI: 3.7, 38]. Those who stayed $<7$ days in the hospital were more likely to have favorable outcome (AOR: 1.7, 95\% CI: 1.6, 16.8) compared to their counterparts. Delayed intervention, prolonged hospital stay and trauma are independent predictors of patient outcomes. Death in Pediatric patients with surgical conditions can be averted by avoiding these delays. Efforts to shorten length of stay in the hospital could also improve patient outcomes.
\end{abstract}

Keywords: Pediatrics, Pediatric Surgery, Outcome, Adama Hospital Medical College, Ethiopia

\section{Introduction}

\subsection{Background}

Pediatric surgical admissions dramatically increased throughout the world as a result of increased trauma, emergency diseases and survival of congenital diseases [1]. Surgical condition is any condition that requires suture, excision, manipulation or other invasive procedure that usually but not always require local, regional or general anesthesia. Surgery is often the only solution to cure or decrease further damage, disability and death in some disease conditions. Surgical diseases are inadequately addressed globally. Both emergency and non emergency surgical conditions contribute substantially to the global burden of mortality and morbidity rates; this is even worse in low income countries [1].

Children develop distinct surgical conditions, present unique anesthetics challenges and have special preoperative need. Moreover, the consequences of pediatric surgical condition may be life long since they affect children at critical times during development. The recognition that the 
surgical need of children differ from those of adults has led to remarkable improvement in care [2].

There is growing evidence that childhood surgical conditions are common in developing countries and that poor care result in significant number of deaths and disability. Unfortunately, pediatric surgical care is not considered as an essential component of most child health programmers. Even if prevention of diseases has many roles in protecting directly or indirectly acquiring congenital or non congenital disease, surgically curable disease of pediatrics also need great emphasis [2, 3].

Pediatric surgical services lack facilities and manpower often resulting in sharing wards, equipment, and nursing staffs with other surgical and even non-surgical specialties. This poses a unique challenge that influences the quality of care and outcome of children with surgical pathology in developing countries [3]. There is increasing intensity of feeling to reverse this trend, by promoting essential surgical services at the referral hospital, the first point of contact for critical conditions for rural and urban populations [4, 5].

Five-years data analyzed by Deribew M. and Adem E. at the largest university hospital in Ethiopia showed that pediatric surgical procedures accounted for $31 \%$ of all operations $(\mathrm{N}=6070)$ and $33 \%$ of all pediatric admissions to the hospital [6].

\subsection{Problem of Statement}

Pediatric surgery has not always been considered as global health problem and health planners and implementers have not given adequate emphasis; but the global health community has recently recognized that surgical condition is significant burden of disease [7]. Surgical intervention plays a major role in preventing death and further chronic disability for those suffering from injuries, emergency abdominal and non abdominal conditions $[8,9]$. Surgery is at the end of the spectrum of the classic curative and preventive medical model [10]. Surgical conditions had been accounted for significant portion of population's disease burden particularly in developing countries where conservative treatment is not readily available [11].

Globally, approximately $28 \%$ of global burden of diseases were amenable to surgical interventions; around half of them were pediatric surgical pathologies. In the Sub-Saharan Africa, the annual presentation rate for all surgical conditions was 543 per 10000 children age $0-14$ years. The estimated cumulative risk for all surgical conditions was $85.4 \%$ by the age of 15 years $[10,11]$.

Out of 234 millions of surgical procedures performed worldwide, only $3.5 \%$ were performed in poorest nations (including Africa) $[12,13]$. Increasing access to surgery and quality of surgical intervention may help to achieve healthy and more productive generations and as well to reduce the potential pediatric age mortality rate [14].

Data are lacking on the spectrum of surgical conditions on the mortality and morbidity associated with lack of surgical services and the burden of pediatric surgical diseases on the health systems [8]. Incomplete information has made it difficult to define an appropriate role for pediatric surgery in Africa, and to assess the impact of surgical diseases on children health [1].

\section{Methods and Materials}

\subsection{Study Area and Period}

The study was conducted in Adama hospital medical college, which is located in Adama town, Oromia Regional State, Ethiopia. The hospital is a teaching referral hospital staffed with five Pediatricians and four Surgeons. There are 75 pediatric beds; 15 beds are dedicated to surgical and orthopedic patients. This study was conducted with the aim of determining the pattern of pediatric surgical admissions and its outcome in Adama hospital medical college from Jun 1,2014 to Jun $30,2015$.

\subsection{Study Design}

Hospital based cross-sectional study design was employed from June 1, 2014 to Jun 30, 2015. All admissions with complete data were included. The data was entered into SPSS version 20 for analysis. Descriptive and analytic statistical methods were utilized. $\mathrm{P}$ value $<0.05$ was considered as statistically significant with $95 \%$ CI.

\section{Results}

\subsection{Socio-Demographic Characteristics}

The mean age of the study participants was 6.09 (SD \pm 4.6$)$ years. Male to female ratio was found to be $2.5: 1$. Nearly $21 \%$ of the participants were under one year of age. $71.1 \%$ $(\mathrm{N}=273)$ of the study units were from rural parts of the region (Table 1).

Table 1. Socio- demographic characteristics of admitted pediatric surgical patients, at AHMC, Jun 1, 2014 - June 30, 2015.

\begin{tabular}{llll}
\hline Variables & Category & Numbers & Percent \\
\hline \multirow{2}{*}{ Sex } & Male & 276 & 71.9 \\
& Female & 108 & 28.1 \\
& $<$ 1 years & 82 & 21.4 \\
Age & 1-4 years & 90 & 23.4 \\
& 5-9 years & 129 & 33.6 \\
\multirow{3}{*}{ Residence } & 10-14.9 years & 83 & 21.6 \\
& Rural & 273 & 71.1 \\
& Urban & 111 & 28.9 \\
\hline
\end{tabular}

\subsection{Patterns of Pediatric Surgical Admissions and Its Outcomes}

Eighty two percent of the admissions were on the emergency bases. The commonest causes of surgical admissions were gastrointestinal conditions $(33.8 \%, \mathrm{~N}=130)$, trauma $(25.5 \%, \mathrm{~N}=98)$ and congenital anomalies $(19 \%$, $\mathrm{N}=73)$. From gastrointestinal conditions, appendicitis $(54 \%$, $\mathrm{N}=70)$ and intestinal obstruction $(30 \%, \mathrm{~N}=39)$ were the commonest diagnoses observed (Table 2).

Scald and flame burn were the major $(85 \%)$ causes of 
burn injury. Fall down injury and road traffic accidents constitute $88 \%$ of all fractures. The most common congenital anomalies were inguinal hernia (38.4\%) and undescended tests $(16.4 \%)$. The most common surgical site infections were any space occupying abscesses (47\%) and osteomyelities (25\%) (Figure 1).

The mean duration of hospitalization was 6.22 days $(\mathrm{SD} \pm$ 5 days). Minor and major operations accounted for $69.3 \%$ $(\mathrm{N}=266)$ while conservative management (orthopedic application, wound care and medication) accounted for
30.7\% ( $=118)$. Unfavorable management outcome occurred in around $19 \%(\mathrm{~N}=69)$ of cases where Surgical Site Infection (SSI) accounts for nearly $93 \%$.

There were 5 deaths giving an overall mortality rate of $1.3 \%$. Complicated intestinal obstructions and congenital anomalies accounted for $80 \%(\mathrm{~N}=4)$ of death. Twenty nine (7.5\%) of admitted patients were referred out to other health institution either for lack of services or self referral. The referred out cases were either congenital anomalies 13 $(44.8 \%)$, burns $14(48.3 \%)$ or head injuries.

Table 2. Distribution of study subjects according to their patterns of surgical admissions and its outcomes at AHMC from Jun 1, 2014 to Jun 30, 2015.

\begin{tabular}{|c|c|c|c|}
\hline Variable & Response category & Number & percent \\
\hline \multirow{2}{*}{ Condition at admission } & Emergency & 315 & 82 \\
\hline & Elective & 69 & 18 \\
\hline \multirow{4}{*}{ Diagnosis during admission $(\mathrm{N}=384)$} & Congenital anomaly & 73 & 19 \\
\hline & Surgical infection & 64 & 16.6 \\
\hline & Gastrointestinal problems & 130 & 33.8 \\
\hline & Others* & 19 & 5.1 \\
\hline \multirow{4}{*}{ Congenital anomalies $(n=73)$} & Club foot & 11 & 15.1 \\
\hline & Undescended tests & 12 & 16.4 \\
\hline & Duodenal atresia & 5 & 6.8 \\
\hline & Others $* *$ & 10 & 10.9 \\
\hline \multirow{4}{*}{$\begin{array}{l}\text { Surgical site infections (SSI) } \\
(n=64)\end{array}$} & Osteomyelities & 16 & 25 \\
\hline & Any space occupying abbesses & 30 & 47 \\
\hline & Cellulites & 11 & 17.2 \\
\hline & Septic arthritis & 7 & 11 \\
\hline \multirow{3}{*}{ Gastrointestinal problems $(\mathrm{n}=130)$} & Appendicitis & 70 & 54 \\
\hline & Pyloric stenosis & 13 & 10 \\
\hline & Others $* * *$ & 8 & 6 \\
\hline \multirow{2}{*}{ Outcome of surgical admission $(\mathrm{N}=355)$} & Favorable outcome & 286 & 80.5 \\
\hline & Un favorable outcome & 69 & 19.4 \\
\hline
\end{tabular}

*Foreign body, Bladder stone, Kidney stone and Sub manidibular cyst and Lypoma

**Anorectal malformation, Malrotation of the gut, Hirschprung diseases and Hypospadias

***Rectal prolapse, Mesenteric lymphadenitis.

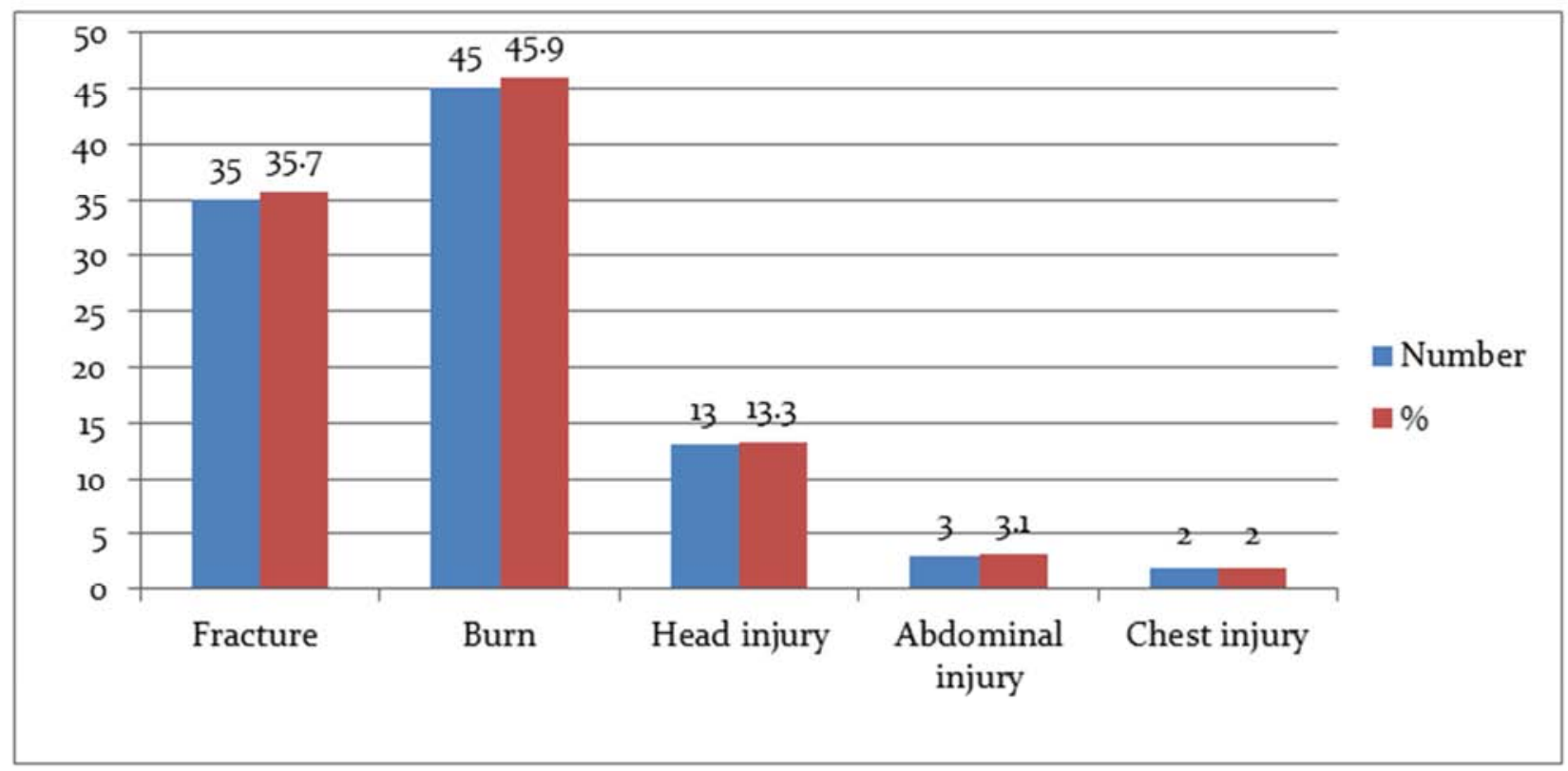

Figure 1. Distribution of types of injuries. 


\subsection{Determinants of Factors Associated with Outcomes of Pediatric Surgical Admissions}

With binary logistic regression urban residents, duration of onset of symptoms $<24$ hours and short lengths of stay in the hospital were predictors of favorable outcomes. However; age, sex and causes of surgical admissions were not associated with outcome of the interventions $(p>0.05)$. Those coming from the urban areas were more likely to have favorable outcome compared to their counterparts [Crude Odds Ratio (COR): 2.96, 95\% CI: $(1.76,4.98)]$. But, after adjusting for other variables it was not found to be significant [AOR: $1.47,95 \% \mathrm{CI}:(0.23,9.6)]$. The time of presentation to intervention ( $<6 \mathrm{hrs}$ ) was found to be significantly associated with the favorable outcome [AOR: $36.4,95 \% \mathrm{CI}$ : $(3.7,38)]$. Those who stayed $<7$ days in the hospital were also significantly associated with favorable outcome [AOR: $1.7,95 \%$ CI: $(1.6,16.8)]$. Those who had $<24$ hours of onset of symptoms were significantly associated with favorable outcome compared to the reference category [COR: 7.73, $95 \%$ CI $(4.65,12.8)]$, but not significant after adjusting for other variables [AOR:, $0.52,95 \%$ CI $(0.86,51.8)]$. Trauma was significantly associated with favorable outcome [AOR: $20.4,95 \%$ CI $(1.99,25.5)]$ compared to other causes of admissions.

Table 3. Factors associated with outcomes of pediatric surgical admissions.

\begin{tabular}{|c|c|c|c|c|}
\hline \multirow{2}{*}{ Variables } & \multicolumn{2}{|c|}{ Outcomes of pediatric surgical admissions } & \multirow{2}{*}{$\operatorname{COR}(95 \% \mathrm{CI})$} & \multirow{2}{*}{ AOR $(95 \% C I)$} \\
\hline & Unfavorable & Favorable & & \\
\hline \multicolumn{5}{|c|}{ Time before intervention } \\
\hline$<6 \mathrm{hrs}$ & $24(24.5 \%)$ & $221(77.3 \%)$ & $10.48(6.13,18) * *$ & $8.00(3.70,13.00) *$ \\
\hline$\geq 6 \mathrm{hrs}$ & $74(75.5 \%)$ & $65(22.7 \%)$ & 1.00 & 1.00 \\
\hline \multicolumn{5}{|c|}{ Length of hospital stay } \\
\hline$<7$ days & $43(44 \%)$ & $251(88 \%)$ & $9.2(5.4,12.2)^{* *}$ & $1.7(1.6,16.8)^{*}$ \\
\hline$\geq 7$ days & $55(56 \%)$ & $35(12 \%)$ & 1.00 & 1.00 \\
\hline \multicolumn{5}{|c|}{ Duration of symptoms } \\
\hline$<24 \mathrm{hrs}$ & $35(36 \%)$ & $232(81 \%)$ & $0.73(4.65,12857)^{*}$ & $0.52(0.86,51.80)$ \\
\hline$\geq 24 \mathrm{hrs}$ & $63(64 \%)$ & $54(19 \%)$ & 1.00 & 1.00 \\
\hline \multicolumn{5}{|c|}{ Area of residency } \\
\hline Urban & $23(23.4 \%)$ & $136(47.5)$ & $2.96(1.76,4.98)^{* *}$ & $1.47(0.023,9.635)$ \\
\hline Rural & $73(74.5 \%)$ & $150(52.4)$ & 1.00 & 1.00 \\
\hline \multicolumn{5}{|l|}{ Case type } \\
\hline Trauma & $19(23 \%)$ & $89(39 \%)$ & $2.20(1.20,3.80)^{*}$ & $20.40(1.90,25.50)^{*}$ \\
\hline Non-trauma & $64(77.1 \%)$ & $139(61 \%)$ & 1.00 & 1.00 \\
\hline
\end{tabular}

NB *p-value $<0.05, * *$ p-value $<0.001$

\section{Discussion}

Boys are more affected than girls even if it is not statistically significant. The studies done in Ethiopian and Nigerian tertiary hospitals also showed the same finding. This could be explained partly by males being more predisposed to both gastrointestinal problems and trauma $[6,8]$. The three most common causes of admissions (gastrointestinal problems, trauma and congenital anomalies) in this study were also found by other similar studies $[4,6]$.

Burn and fracture cases constitute the leading causes of trauma. Scald and flame burns are the commonest types $(85 \%)$ of burn cases while fall down and road traffic accidents constitute the major $(88 \%)$ causes of fracture. This is in line with the study done by Simmons D. where $27 \%$ and $32 \%$ of accidents were caused by scald burns and fractures respectively [15]. The common cause of fracture in Simmons's study was fall accident while it is road traffic accident in our study. This could be because Adama town is found on the high traffic corridor of the country [16].

From congenital anomalies, inguinal hernias are the most common encounters. This is similar to different studies conducted in Africa [4,9]. But, the second most common congenital malformation in these studies, meningomyelocele, was not encountered likely because these malformations are referred to other centers.

In this study, unfavorable outcomes (death or surgical site infection) rate was $19.4 \%$. This result is lower than the study done in Nigeria where a total of 56 patients were operated for intussusceptions at Buganda Medical Centre and $37.5 \%$ of them developed surgical site infection (the most frequent complication in the study) [17]. Death was observed in $1.3 \%$ of cases. It is slightly lower than the study by Osifo OD and Aduwa IP where 3\% mortality rate was reported [8]. But it is much lower than the $7.46 \%$ reported mortality rate from a study in a zonal hospital (Yirgalem) in the same country to this study. The smaller sample size in this study $(\mathrm{N}=134)$ might have affected the result [18].

Duration of symptoms at presentation (dichotomized at 24 hours) and area of residency (rural/urban) were only statistically significant by bivariate logistic regression. Independent predictors of unfavorable outcomes were length of hospitalization for $>7$ days, the time of 
presentation to intervention ( $>6 \mathrm{hrs}$ ) and trauma patients. The study done by Osifo AD and Aduwa IP at Buganda Medical Centre also showed that delayed presentation and associated surgical site infections were predictors of mortality in admitted pediatric surgical patients [8].

\section{Conclusion}

The common causes of admissions into pediatric surgical wards at the study site are gastrointestinal conditions, trauma and congenital anomalies.

SSI is very high in our study. Even if it is not direct predictor of patients' outcome in our study, clearly it will contribute to prolonged length of hospitalization. Delayed time of intervention of more than six hours, prolonged time of hospitalization for more than seven days and trauma are independent predictors of patient outcomes. Death in Pediatric patients with surgical conditions can be averted by avoiding these delays. Effort should be made to minimize the rate of surgical site infections. Reasons and ways to decrease length of hospital stay must be sought.

\section{References}

[1] Nordberg E (1994). Injuries in Africa: A review. East African Medical Journal 71: 339-45.

[2] Division of Pediatric Surgery, Center for Pediatric Surgical Clinical Trials \& Outcomes Research, Johns Hopkins University School of Medicine (2004) 125-130.

[3] Ameh EA, Chirdan LB (2001). Paediatric surgical in the rural setting: prospect and feasibility. West Africa journal of Medicine 201: 52-5.

[4] Bicker SW, Rode H (2001). Pediatric surgery in subSaharan Africa. Pediatric surgery international 17: 442-7.

[5] Nwomeh BC, Mshelbwala PM (2004). Paediatric surgical specialty: how relevant to Africa? Afr J Paediatr Surg 1: 36-42.
[6] Derebew M. and Ahmed E (2006). Pattern of paediatrics surgical condition at BLH, AAU Medical Faculty. Ethiop Med. J. 44 (4): $331-8$.

[7] Thanni OA, Shonubi AMO, Akiode O (2005). A retrospective audit of pediatric surgical admission in a sub-urban tertiary hospital. West Afr J Med 24: 10-12.

[8] Osifo OD, Aduwa IP (2010). Pattern and outcome of paediatric surgical admission to a Nigerian tertiary hospital Annals of Pediatric Surgery 6; 161-166.

[9] Bickler SW, Sanno-Duand B (2000). Epidemiology of pediatric surgical admission to a government referral hospital in the Gambia. Bulletin of the World Health Organ. 78: 13306.

[10] Bickler SW, Rode H (2002). Surgical services for children in developing countries. Bull World Health Organ 80 (10): 829 835 .

[11] Bickler SW, Telfer ML, Sanno-Duanda B (2003). Need for paediatric surgery care in an urban area of The Gambia. Trop Doct 33 (2): 91-94.

[12] Weiser TG, Regenbogen SE, Thompson KD, et al (2008). An estimation of the global volume of surgery: a modelling strategy based on available data. Lancet 372 (9633): 139-144.

[13] Azzie G, Bickler S, Farmer D, Beasley S (2008). Partnerships for developing pediatric surgical care in low-income countries. J Pediatr Surg 43 (12): 2273-2274.

[14] Graham RJ (2008). Specialty services for children with special health care needs. Arch Dis Child 93: 2-4.

[15] Simons D (1985). Accidents in Malawi. Archives of disease in childhood 60: 64-66.

[16] Assefa et al (2014). Magnitude of, trends in, and associated factors of road traffic collision in central Ethiopia. BMC Public Health 14: 1072.

[17] Chalya et al (2014). Childhood intussaucception. Italian Journal of Pediatrics 40: 28.

[18] Tekle TT, Mollalegne TM (2016). Pattern of Pediatric Surgical Admission in Yirgalem Hospital, Southern Ethiopia. J Vasc Med Surg 4: 239. 